\title{
Associations with rates of falls among home care clients in Ontario, Canada: a population-based, cross-sectional study
}

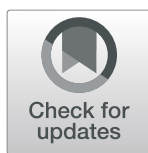

\author{
Derek R. Manis ${ }^{1,2^{*}}$ (D), Caitlin McArthur ${ }^{3,4}$ (D) and Andrew P. Costa ${ }^{1,2,3}$ (D)
}

\begin{abstract}
Background: Accidental falls among older adults are a leading cause of injury-related hospitalizations. Reducing falls is an ongoing quality improvement priority for home care, given that many home care clients experience falls. In this study, we identify factors associated with the rate of falls among home care clients.

Methods: We conducted a population-based, cross-sectional study using secondary data from the Hamilton, Niagara, Haldimand, and Brant health region of Ontario, Canada from January 1 - March 31, 2018. We captured person-level characteristics with falls from the Resident Assessment Instrument - Home Care (RAl-HC). Negative binomial regression was used to model the rate of falls.

Results: Functional characteristics of home care clients had strong, statistically significant associations with the rate of falls. Declines in activities of daily living, assistive device use for locomotion indoors, polypharmacy, and health conditions, such as dizziness or lightheadedness, and parkinsonism, were associated with a higher rate of falls. Males who used assistive devices had a higher rate of falls compared to females; however, males with neurological and cardiovascular health conditions had a decrease in the rate of falls compared to females. Home care clients with parkinsonism who used a cane and took eight or more drugs had stronger associations with an increased rate of falls compared to those who do not have parkinsonism.

Conclusions: Functional characteristics, polypharmacy, and health conditions are associated with increased rates of falls among home care clients. Home care clients who are at a greater risk of falls may require environmental adjustments in their home to reduce or eliminate the possibility of falling.
\end{abstract}

Keywords: Accidental falls, Home care, Older adults, Assistive devices, Canada

\section{Introduction}

Accidental falls are the predominant cause of all injuryrelated hospitalizations among older adults in Canada [1]. Accidental falls also adversely affect mental health, resulting in decreased independence and autonomy, and increased fear of falling, increased isolation, and depression [1-5]. Falls are also important predictors of older adults becoming institutionalized (i.e., admission to long-term care) [6]. In Ontario, home care services are predominately provided by the provincial government

\footnotetext{
* Correspondence: manisd@mcmaster.ca

${ }^{1}$ Centre for Health Economics and Policy Analysis, McMaster University, 1280

Main Street West, CRL-201, Hamilton, ON L8S 4K1, Canada

${ }^{2}$ Department of Health Research Methods, Evidence, and Impact, McMaster

University, Hamilton, Canada

Full list of author information is available at the end of the article
}

under its universal, public health insurance plan to support older adults in receiving the care services they need (e.g., nursing, physiotherapy, occupational therapy, social work, etc.) to remain in their home and community [7]. Reducing falls is an ongoing quality improvement priority for home care, given that many home care clients experience falls $[8,9]$.

Among home care clients in Ontario, Canada, risk factors for falls have been investigated among those with neurological conditions (i.e., dementia, parkinsonism) [10]. In addition, many chronic health conditions have been investigated in the context of home care and quality of life [11]. However, an explanatory investigation of multiple person-level characteristics with the rate of falls has not been conducted with recent data on home care 
clients. Person-level factors are important to investigate because these factors contribute to the development and implementation of strategies to prevent falls from occurring. Falls are also multifactorial, and so it is necessary to investigate multiple factors to identify clustering characteristics to classify patient groups that need more clinical focus to prevent falls. The rate of falls is important because it identifies the frequency of falling, which has implications for improving patient safety and quality of care in the home care setting.

Our study objective was to investigate the associations between person-level characteristics and the rate of falls among home care clients. We hypothesized that home care clients with polypharmacy, impaired cognition, declines in activities of daily living, and neurological disorders (i.e., Alzheimer's, dementia, multiple sclerosis, and parkinsonism) were associated with falls in this population. Our secondary objective was to examine differences between males and females, and to examine differences between different high-risk subgroups (e.g., parkinsonism, etc.).

\section{Methods}

\section{Study design, setting, and participants}

We conducted a population-based, cross-sectional study in the Hamilton, Niagara, Haldimand, and Brant (HNHB) health region of Ontario, Canada. This region services over 1.4 million residents, of which $27 \%$ of the population is over the age of 65 [12]. Home care clients in the HNHB health region who received any type of home care assessment (e.g., initial assessment, follow-up, change in status, etc.) during the January 1, 2018 to March 31, 2018 period were included in our study. Only the first assessment for each home care client during the study period was included in our analysis.

\section{Data source}

The Resident Assessment Instrument - Home Care (RAI-HC) is an assessment from interRAI for use with older adults who receive home care or are in a community-based setting. This assessment includes severity scales pertaining to cognitive, hearing, vision, mood and behavior patterns, and activities of daily living. It also captures health status (e.g., chronic health conditions and medications, preventive health measure, etc.), environmental assessment, and health service utilization [13]. The RAI-HC assessment is a valid and reliable instrument, has strong test/re-test reliability, and has been used in other studies investigating falls among home care clients $[12,14]$.

\section{Variables}

The outcome variable, falls frequency, specifies the number of falls experienced by the home care client in the last 90 days. This variable is a count variable ranging from zero to nine, where nine or more falls is reported as nine. Predictor variables were selected using a combination of clinical judgment and an assessment of related literature on home care clients and adverse events in the home $[1,11,15-18]$. Demographic (e.g., age, sex, etc.), functional (e.g., cognitive skills, activities of daily living, assistive device use, etc.), and number of drugs taken and diagnoses (e.g., cardiovascular, neurological, musculoskeletal, etc.) were person-level characteristics included in the final model to determine the associations with falls among home care clients.

\section{Statistical methods}

Sample size was calculated based on at least 20 events per predictor variable $(n \geq 820)$ [19]. Descriptive statistics (i.e., frequencies, percentages, and 95\% confidence intervals) were calculated for all categorical variables in the model. No continuous variables were used; age and number of drugs taken by home care clients were transformed into categorical variables in 10-year and 2medication intervals, respectively, to support clinical relevance, importance, and easier interpretation of the results. The outcome variable was not normally distributed; rather than transforming it, which would limit clinical interpretation of the results, negative binomial regression was used. Negative binomial regression was preferred to Poisson and Quasi-Poisson regression, given that the variance was greater than the mean.

Variable selection was performed by comparing Akaike Information Criterion between demographic and functional characteristics of home care clients and different groups of diagnoses (i.e., cardiovascular, neurological, musculoskeletal). An $\alpha=0.05$ was used for statistical significance for testing variables. Variance inflation factors were assessed for all variables. Interactions between sex and all predictors in the final model were assessed because of the differences that exist between males and females for various health conditions included in the final model (e.g., cardiovascular, musculoskeletal, etc.), and these interactions may additionally have an impact on associations with the rate of falls. Statistically significant interactions at $\alpha=0.001$ were reported. Outliers were assessed by examining standardized residuals with values greater than two. Data set processing was conducted in SAS Enterprise 9.4 (Cary, North Carolina, USA) and statistical analyses were conducted in $\mathrm{R}$ version 3.5.3 (Vienna, Austria) [20-29].

\section{Results}

There were 10,586 home care clients in the HNHB health region who received an assessment during the January 1, 2018 to March 31, 2018 period $(n=10,586)$. The were no missing data, given that the RAI-HC is the 
basis for electronic medical records in the home care setting and assessment fields are mandatory [30]. The outcome variable, falls frequency in the last 90 days, was skewed to the right. Fifty-two per cent of the sample $(n=5481)$ did not experience a fall, whereas $40 \%(n=$ 4214) experienced one to three falls. Six per cent of the sample $(n=649)$ experienced four to eight falls, and $2 \%$ of the sample $(n=242)$ experienced nine or more falls.

\section{Description of population-based sample}

Table 1 describes our population-based sample of home care clients in the HNHB health region. Home care clients were predominately female $(n=6462,61 \%)$, between the ages of $80-89(n=3920,37 \%)$ and were widowed $(n=4363,41 \%)$. Some home care clients had minimally impaired cognitive skills for daily decisionmaking ( $n=2228,21 \%$ ), but most had declines in activities of daily living $(n=6915,65 \%)$, used a walker or crutch for locomotion indoors $(n=4804,45 \%)$, and were unable to go up and down the stairs $(n=6332,60 \%)$. Over half of our sample took eight or more drugs $(n=$ $6744,64 \%)$, and many experienced dizziness or lightheadedness $(n=2795,26 \%)$, edema $(n=3726,35 \%)$, and shortness of breath $(n=3533,33 \%)$.

\section{Associations with the rate of falls}

Table 2 describes the adjusted associations with the rate of falls among our population-based sample of home care clients in the HNHB health region. All variables had a variance inflation factor less than 1.6, indicating that multicollinearity was not present in the final model. A sensitivity analysis was not conducted because $1 \%$ of observations $(n=153)$ had a standardized residual greater than two.

Functional characteristics had statistically significant associations with the rate of falls. In particular, declines in activities of daily living were associated with an increased rate of falls (IRR $=1.59$, 95\% CI 1.49, 1.69; $p<0.001)$. The use of assistive devices for locomotion indoors also had statistically significant associations with the rate of falls among our sample: scooter (IRR $=2.26$, 95\% CI 1.42, 3.71; $p<0.001)$, walker or crutch (IRR = $1.50,95 \%$ CI 1.37, 1.63; $p<0.001)$, cane (IRR $=1.42$, 95\% CI 1.28, 1.59; $p<0.001$ ), and wheelchair (IRR = $1.35,95 \%$ CI $1.21,1.51 ; p<0.001)$ use were all associated with an increased rate of falls. Moderately impaired cognitive skills for daily decision-making were also associated with a $38 \%$ increase in the rate of falls (IRR $=1.38$, 95\% CI 1.24, 1.54; $p<0.001)$.

Polypharmacy and health conditions had statistically significant associations with the rate of falls. Home care clients who took eight or more drugs had a $21 \%$ increase in the rate of falls $(\mathrm{IRR}=1.21,95 \%$ CI 1.05, 1.39; $p=$ 0.007 ), and those who experienced dizziness or
Table 1 Characteristics of home care clients in HNHB health region, Jan $1-\operatorname{Mar} 31,2018(n=10,586)$

\begin{tabular}{|c|c|c|}
\hline & $\%(n)$ & $95 \% \mathrm{Cl}(\%)$ \\
\hline \multicolumn{3}{|l|}{ Demographic Characteristics } \\
\hline \multicolumn{3}{|l|}{ Sex } \\
\hline Male & $39(4160)$ & 38,40 \\
\hline Female & $61(6462)$ & 60,62 \\
\hline \multicolumn{3}{|l|}{ Age } \\
\hline$<60$ & $9(949)$ & $8.4,9.5$ \\
\hline $60-69$ & $12(1246)$ & 11,12 \\
\hline $70-79$ & $22(2301)$ & 21,23 \\
\hline $80-89$ & 37 (3920) & 36,38 \\
\hline $90-99$ & $20(2114)$ & 19,21 \\
\hline$\geq 100$ & $0.5(56)$ & $0.4,0.69$ \\
\hline \multicolumn{3}{|l|}{ Marital Status } \\
\hline Never married & $8.6(913)$ & $8.1,9.2$ \\
\hline Married & 38 (3972) & 37,38 \\
\hline Widowed & $41(4363)$ & 40,42 \\
\hline Separated & $2.9(302)$ & $2.5,3.2$ \\
\hline Divorced & $8.1(861)$ & $7.6,8.7$ \\
\hline Other & $1.7(175)$ & $1.4,1.9$ \\
\hline \multicolumn{3}{|l|}{ Functional Characteristics } \\
\hline \multicolumn{3}{|l|}{ Cognitive Skills for Daily Decision-Making } \\
\hline Independent & $33(3465)$ & 32,34 \\
\hline Modified Independent & $27(2830)$ & 26,28 \\
\hline Minimally Impaired & $21(2228)$ & 20,22 \\
\hline Moderately Impaired & $12(1314)$ & 12,13 \\
\hline Severely Impaired & $7.1(749)$ & $6.6,7.6$ \\
\hline Activities of Daily Living Decline & $65(6915)$ & 64,66 \\
\hline \multicolumn{3}{|l|}{ Primary Modes of Locomotion (Indoors) } \\
\hline No Assistive Device & $27(2888)$ & 26,28 \\
\hline Cane & $10(1077)$ & $9.6,10.8$ \\
\hline Walker/Crutch & $45(4804)$ & 44,46 \\
\hline Scooter & $0.31(33)$ & $0.22,0.44$ \\
\hline Wheelchair & $15(1621)$ & 15,16 \\
\hline Activity did not occur & $1.5(163)$ & $1.3,1.8$ \\
\hline \multicolumn{3}{|l|}{ Stair Climbing } \\
\hline Up and Down Stairs Without Help & $22(2364)$ & 22,23 \\
\hline Up and Down Stairs with Help & $18(1890)$ & 17,19 \\
\hline Not go up and down stairs & $60(6332)$ & 59,61 \\
\hline \multicolumn{3}{|l|}{ Polypharmacy and Health Conditions } \\
\hline \multicolumn{3}{|l|}{ Drugs } \\
\hline $0-2$ & $5.7(602)$ & $5.3,6.1$ \\
\hline $3-4$ & $8.3(876)$ & $7.8,8.8$ \\
\hline $5-7$ & $22(2364)$ & 22,23 \\
\hline$\geq 8$ & 64 (6744) & 63,65 \\
\hline
\end{tabular}


Table 1 Characteristics of home care clients in HNHB health region, Jan 1 - Mar 31, $2018(n=10,586)$ (Continued)

\begin{tabular}{lll}
\hline & $\%(n)$ & $95 \% \mathrm{Cl}(\%)$ \\
\hline Stroke & $18(1914)$ & 17,19 \\
Congestive Heart Failure & $14(1458)$ & 13,14 \\
Hypertension & $66(6956)$ & 65,67 \\
Irregular Pulse & $19(2000)$ & 18,20 \\
Peripheral Vascular Disease & $9.2(969)$ & $8.6,9.7$ \\
Chest Pain at Rest or on Exertion & $4.4(464)$ & $4.0,4.8$ \\
Dizziness or Lightheadedness & $26(2795)$ & 26,27 \\
Edema & $35(3726)$ & 34,36 \\
Shortness of Breath & $33(3533)$ & 32,34 \\
Alzheimer's & $6.5(684)$ & 6,7 \\
Dementia & $22(2337)$ & 21,23 \\
Multiple Sclerosis & $1.5(159)$ & $1.3,1.8$ \\
Parkinsonism & $4.3(456)$ & $3.9,4.7$ \\
Arthritis & $56(5900)$ & 55,57 \\
Hip Fracture & $4.4(464)$ & $4.0,4.8$ \\
\hline
\end{tabular}

95\% Cl 95\% Confidence Interval

lightheadedness had a $43 \%$ increase in the rate of falls $(\mathrm{IRR}=1.43,95 \%$ CI 1.33, 1.52; $p<0.001)$. Home care clients who have parkinsonism had a $46 \%$ increase in the rate of falls (IRR $=1.46,95 \%$ CI 1.28, 1.67; $p<0.001)$.

\section{Sex differences}

Table 3 describes important differences between males and females observed within functional characteristics. The distribution of age between males and females in our population-based sample is comparable, and so the differences found are attributable to sex, rather than to age. Males who used assistive devices had a higher rate of falls compared to females who used assistive devices for locomotion indoors. For example, males who used a walker or crutch had a $61 \%$ increase in the rate of falls $(\mathrm{IRR}=1.61,95 \%$ CI 1.60, 1.67; $p<0.001)$, whereas females had a $43 \%$ increase (IRR $=1.43,95 \%$ CI 1.31, 1.45; $p=0.050$ ). Males who used a cane had a $60 \%$ increase in the rate of falls (IRR $=1.60,95 \%$ CI 1.60, 1.67; $p<0.001)$, compared to females who had a $28 \%$ increase (IRR = 1.28, 95\% CI 1.23, 1.31; $p=0.039)$.

Differences between males and females were also observed within neurological and cardiovascular health conditions. Specifically, males with these health conditions had a decrease in the rate of falls compared to females with the same conditions. For example, males who had a stroke had an $18 \%$ decrease in the rate of falls (IRR $=0.82,95 \%$ CI 0.78, 0.92; $p<0.001$ ), whereas females had a $3 \%$ decrease $(\mathrm{IRR}=0.97,95 \%$ CI $0.92,1.00 ; p=0.032)$. Males with congestive heart failure had a $25 \%$ decrease in the
Table 2 Adjusted associations with the rate of falls among home care clients in HNHB health region, Jan 1 - Mar 31, 2018 $(n=10,586)$

\begin{tabular}{llll}
\hline & IRR & $95 \%$ Cl & $P$ Value \\
\hline $\begin{array}{l}\text { Demographic Characteristics } \\
\text { Male }\end{array}$ & 1.001 .00 & 1.00 \\
Female & 0.83 & $0.78,0.89<0.001$ \\
Age & & & \\
$<60$ (Reference) & 1.00 & 1.00 & 1.00 \\
$60-69$ & 0.88 & $0.77,1.00$ & 0.054 \\
$70-79$ & 0.71 & $0.63,0.81<0.001$ \\
$80-89$ & 0.70 & $0.61,0.79<0.001$ \\
$90-99$ & 0.70 & $0.61,0.80$ & $<0.001$ \\
$\geq 100$ & 0.57 & $0.37,0.88$ & 0.011 \\
Marital Status & & & \\
Never Married & 0.94 & $0.83,1.06$ & 0.277 \\
Married (Reference) & 1.00 & 1.00 & 1.00 \\
Widowed & 0.98 & $0.91,1.05$ & 0.520 \\
Separated & 1.25 & $1.05,1.49$ & 0.012 \\
Divorced & 1.06 & $0.95,1.19$ & 0.283 \\
Other & 1.21 & $0.97,1.51$ & 0.096
\end{tabular}

Functional Characteristics

Cognitive Skills for Daily Decision-Making Independent (Reference)

$\begin{array}{lll}1.00 & 1.00 \quad 1.00\end{array}$

Modified Independence

$1.14 \quad 1.05,1.23 \quad 0.001$

Minimally Impaired

Moderately Impaired

$1.281 .18,1.40<0.001$

$1.381 .24,1.54<0.001$

Severely Impaired

Activities of Daily Living Decline

$1.19 \quad 1.04,1.37 \quad 0.013$

$1.591 .49,1.69<0.001$

Primary Modes of Locomotion (Indoors)

No Assistive Device (Reference)

$\begin{array}{lll}1.00 & 1.00 \quad 1.00\end{array}$

Cane

Walker/Crutch

$1.421 .28,1.59<0.001$

$1.501 .37,1.63<0.001$

Scooter

$2.261 .42,3.71<0.001$

Wheelchair

Activity Did Not Occur

$1.351 .21,1.51<0.001$

$1.06 \quad 0.83,1.37 \quad 0.626$

Stair Climbing

Up and Down Stairs No Help (Reference) $1.00 \quad 1.00 \quad 1.00$

Up and Down Stairs with Help

$1.221 .10,1.34<0.001$

Not Go Up and Down Stairs

$1.221 .11,1.33<0.001$

Polypharmacy and Health Conditions

Drugs

$\begin{array}{llll}0-2 \text { (Reference) } & 1.00 & 1.00 & 1.00 \\ 3-4 & 1.21 & 1.03,1.43 & 0.022 \\ 5-7 & 1.11 & 0.96,1.29 & 0.153 \\ \geq 8 & 1.21 & 1.05,1.39 & 0.007\end{array}$


Table 2 Adjusted associations with the rate of falls among home care clients in HNHB health region, Jan 1 - Mar 31, 2018 $(n=10,586)$ (Continued)

\begin{tabular}{llll}
\hline & IRR & $95 \%$ Cl & $P$ Value \\
\hline Stroke & 0.91 & $0.84,0.98$ & 0.013 \\
Congestive Heart Failure & 0.86 & $0.78,0.94$ & $<0.001$ \\
Hypertension & 0.99 & $0.93,1.06$ & 0.840 \\
Irregular Pulse & 1.00 & $0.92,1.08$ & 0.944 \\
Peripheral Vascular Disease & 0.96 & $0.87,1.07$ & 0.489 \\
Chest Pain/Pressure at Rest or on Exertion & 1.11 & $0.97,1.28$ & 0.139 \\
Dizziness or Lightheadedness & 1.43 & $1.33,1.52$ & $<0.001$ \\
Edema & 1.01 & $0.94,1.07$ & 0.854 \\
Shortness of Breath & 0.92 & $0.86,0.98$ & 0.013 \\
Alzheimer's & 0.80 & $0.70,0.92$ & 0.001 \\
Dementia & 1.02 & $0.94,1.11$ & 0.642 \\
Multiple Sclerosis & 1.09 & $0.86,1.38$ & 0.485 \\
Parkinsonism & 1.46 & $1.28,1.67$ & $<0.001$ \\
Arthritis & 1.04 & $0.98,1.11$ & 0.189 \\
Hip Fracture & 1.13 & $0.98,1.29$ & 0.084 \\
\hline
\end{tabular}

IRR Incident Rate Ratios, 95\% Cl 95\% Confidence Interval

rate of falls $(\mathrm{IRR}=0.75,95 \%$ CI $0.70,0.83 ; p<0.001)$, whereas females had a $4 \%$ decrease (IRR $=0.94,95 \%$ CI $0.89,1.00 ; p=0.012$ ).

\section{Subgroup analyses}

Tables 4, 5 and 6 (available as online appendices) describe the subgroup analyses of health conditions that were statistically significant $(p<0.001)$ in the final, adjusted model (i.e., parkinsonism, dizziness and/or lightheadedness, and congestive heart failure). Among home care clients with parkinsonism, the use of a cane was associated with a $129 \%$ increase in the rate of falls, compared to home care clients with parkinsonism who did not use an assistive device (IRR $=2.29,95 \%$ CI 1.37, 3.86; $p=0.001$ ). Conversely, the rate of falls among home care clients who do not have a parkinsonism diagnosis and use a cane for locomotion indoors was 39\% higher $(\mathrm{IRR}=1.39,95 \%$ CI 1.24, 1.56; $p<0.001)$. There were also differences between home care clients with parkinsonism and the number of drugs they took and rates of falls. Home care clients with parkinsonism who took eight or more drugs had a $177 \%$ increase in the rate of falls (IRR $=2.77,95 \%$ CI 1.13, 6.96; $p=0.027$ ), compared to those who do not have parkinsonism (IRR $=1.18,95 \%$ CI 1.03, 1.36; $p=0.021)$. In the subgroup analyses of home care clients who experienced dizziness and/or lightheadedness and have congestive heart failure, the findings of these analyses were similar to those who did not experience dizziness and/or lightheadedness and congestive heart failure.
Table 3 Adjusted sex differences among male and female home care clients

\begin{tabular}{|c|c|c|c|}
\hline & IRR & $95 \% \mathrm{Cl}$ & $P$ Value \\
\hline \multicolumn{4}{|c|}{ Functional Characteristics } \\
\hline \multicolumn{4}{|c|}{ Cognitive Skills for Daily Decision-Making - Minimally Impaired } \\
\hline Males & 1.42 & $1.40,1.47$ & $<0.001$ \\
\hline Females & 1.17 & $1.16,1.18$ & 0.035 \\
\hline \multicolumn{4}{|c|}{ Cognitive Skills for Daily Decision-Making - Moderately Impaired } \\
\hline Males & 1.41 & $1.40,1.47$ & $<0.001$ \\
\hline Females & 1.39 & $1.25,1.40$ & 0.560 \\
\hline \multicolumn{4}{|c|}{ Activities of Daily Living Decline } \\
\hline Males & 1.54 & $1.52,1.68$ & $<0.001$ \\
\hline Females & 1.58 & $1.55,1.67$ & 0.945 \\
\hline \multicolumn{4}{|c|}{ Primary Modes of Locomotion Indoors - Cane } \\
\hline Males & 1.60 & $1.58,1.67$ & $<0.001$ \\
\hline Females & 1.28 & $1.23,1.31$ & 0.039 \\
\hline \multicolumn{4}{|c|}{ Primary Modes of Locomotion Indoors - Walker/Crutch } \\
\hline Males & 1.61 & $1.60,1.67$ & $<0.001$ \\
\hline Females & 1.43 & $1.31,1.45$ & 0.050 \\
\hline \multicolumn{4}{|c|}{ Primary Modes of Locomotion Indoors - Wheelchair } \\
\hline Males & 1.47 & $1.44,1.53$ & $<0.001$ \\
\hline Females & 1.30 & $1.29,1.31$ & 0.275 \\
\hline \multicolumn{4}{|l|}{ Health Conditions } \\
\hline \multicolumn{4}{|l|}{ Stroke } \\
\hline Males & 0.82 & $0.78,0.92$ & 0.001 \\
\hline Females & 0.97 & $0.92,1.00$ & 0.032 \\
\hline \multicolumn{4}{|c|}{ Congestive Heart Failure } \\
\hline Males & 0.75 & $0.70,0.83$ & $<0.001$ \\
\hline Females & 0.94 & $0.89,1.00$ & 0.012 \\
\hline \multicolumn{4}{|c|}{ Dizziness or Lightheadedness } \\
\hline Males & 1.45 & $1.44,1.56$ & $<0.001$ \\
\hline Females & 1.38 & $1.32,1.43$ & 0.517 \\
\hline \multicolumn{4}{|l|}{ Parkinsonism } \\
\hline Males & 1.53 & $1.32,1.69$ & $<0.001$ \\
\hline Females & 1.28 & $1.10,1.53$ & 0.280 \\
\hline
\end{tabular}

IRR Incident Rate Ratios, 95\% CI 95\% Confidence Interval

\section{Discussion}

\section{Principal findings}

We investigated the associations with person-level characteristics and the rate of falls among home care clients using routinely collected data in Ontario, Canada. Declines in activities of daily living, the use of assistive devices (i.e., scooter, walker/crutch, cane, and wheelchair), impaired cognitive skills for daily decision-making, parkinsonism, and experiencing dizziness or lightheadedness were all associated with an increased rate of falls. Males who used assistive devices for mobility indoors had higher rates of falls 
Table 4 Subgroup analysis of home care clients with and without Parkinsonism in HNHB health region, Jan 1-Mar 31, 2018

\begin{tabular}{|c|c|c|c|c|c|c|}
\hline \multirow{3}{*}{ Demographic Characteristics } & \multicolumn{3}{|c|}{ Has Parkinsonism $(n=456)$} & \multicolumn{3}{|c|}{ Does Not Have Parkinsonism $(n=10,103)$} \\
\hline & \multirow[t]{2}{*}{ IRR } & \multirow[t]{2}{*}{$95 \% \mathrm{Cl}$} & \multirow[t]{2}{*}{$P$ Value } & \multirow[t]{2}{*}{ IRR } & \multirow[t]{2}{*}{$95 \% \mathrm{Cl}$} & \multirow[t]{2}{*}{$P$ Value } \\
\hline & & & & & & \\
\hline Male & 1.00 & 1.00 & 1.00 & 1.00 & 1.00 & 1.00 \\
\hline Female & 0.69 & $0.53,0.91$ & 0.001 & 0.84 & $0.78,0.89$ & $<0.001$ \\
\hline \multicolumn{7}{|l|}{ Age } \\
\hline$<60$ & 1.00 & 1.00 & 1.00 & 1.00 & 1.00 & 1.00 \\
\hline $60-69$ & 1.67 & $0.58,4.73$ & 0.282 & 0.87 & $0.76,0.99$ & 0.034 \\
\hline $70-79$ & 1.13 & $0.39,3.19$ & 0.801 & 0.72 & $0.63,0.82$ & $<0.001$ \\
\hline $80-89$ & 1.25 & $0.44,3.50$ & 0.637 & 0.69 & $0.61,0.79$ & $<0.001$ \\
\hline $90-99$ & 0.87 & $0.29,2.60$ & 0.794 & 0.70 & $0.60,0.80$ & $<0.001$ \\
\hline$\geq 100$ & 0 & 0 & 0 & 0.57 & $0.37,0.88$ & 0.011 \\
\hline \multicolumn{7}{|l|}{ Marital Status } \\
\hline Never Married & 1.05 & $0.62,1.81$ & 0.868 & 0.94 & $0.83,1.07$ & 0.340 \\
\hline Married & 1.00 & 1.00 & 1.00 & 1.00 & 1.00 & 1.00 \\
\hline Widowed & 1.00 & $0.72,1.38$ & 0.979 & 0.98 & $0.90,1.05$ & 0.535 \\
\hline Separated & 1.11 & $0.39,3.44$ & 0.832 & 1.25 & $1.05,1.50$ & 0.012 \\
\hline Divorced & 0.86 & $0.51,1.45$ & 0.570 & 1.08 & $0.96,1.21$ & 0.203 \\
\hline Other & 1.18 & $0.35,4.66$ & 0.768 & 1.23 & $0.98,1.54$ & 0.075 \\
\hline \multicolumn{7}{|l|}{ Functional Characteristics } \\
\hline \multicolumn{7}{|c|}{ Cognitive Skills for Daily Decision-Making } \\
\hline Independent & 1.00 & 1.00 & 1.00 & 1.00 & 1.00 & 1.00 \\
\hline Modified Independence & 1.09 & $0.75,1.58$ & 0.626 & 1.14 & $1.05,1.50$ & 0.001 \\
\hline Minimally Impaired & 1.45 & $0.97,2.16$ & 0.053 & 1.28 & $1.17,1.40$ & $<0.001$ \\
\hline Moderately Impaired & 1.27 & $0.78,2.07$ & 0.315 & 1.39 & $1.24,1.55$ & $<0.001$ \\
\hline Severely Impaired & 0.96 & $0.54,1.71$ & 0.893 & 1.20 & $1.04,1.39$ & 0.012 \\
\hline Activities of Daily Living Decline & 1.20 & $0.88,1.63$ & 0.236 & 1.61 & $1.51,1.72$ & $<0.001$ \\
\hline \multicolumn{7}{|c|}{ Primary Modes of Locomotion (Indoors) } \\
\hline No Assistive Device & 1.00 & 1.00 & 1.00 & 1.00 & 1.00 & 1.00 \\
\hline Cane & 2.29 & $1.37,3.86$ & 0.001 & 1.39 & $1.24,1.56$ & $<0.001$ \\
\hline Walker/Crutch & 1.90 & $1.28,2.83$ & 0.001 & 1.47 & $1.35,1.61$ & $<0.001$ \\
\hline Scooter & 0.88 & $0.16,5.25$ & 0.880 & 2.43 & $1.49,4.07$ & $<0.001$ \\
\hline Wheelchair & 1.60 & $0.98,2.60$ & 0.055 & 1.34 & $1.20,1.50$ & $<0.001$ \\
\hline Activity Did Not Occur & 0.14 & $0.00,0.88$ & 0.077 & 1.09 & $0.84,1.41$ & 0.500 \\
\hline \multicolumn{7}{|l|}{ Stair Climbing } \\
\hline Up and Down Stairs No Help & 1.00 & 1.00 & 1.00 & 1.00 & 1.00 & 1.00 \\
\hline Up and Down Stairs with Help & 1.31 & $0.81,2.11$ & 0.250 & 1.21 & $1.09,1.34$ & $<0.001$ \\
\hline Not Go Up and Down Stairs & 1.16 & $0.73,1.82$ & 0.521 & 1.23 & $1.12,1.34$ & $<0.001$ \\
\hline \multicolumn{7}{|l|}{ Polypharmacy and Health Conditions } \\
\hline \multicolumn{7}{|l|}{ Drugs } \\
\hline $0-2$ & 1.00 & 1.00 & 1.00 & 1.00 & 1.00 & 1.00 \\
\hline $3-4$ & 3.53 & $1.34,9.56$ & 0.010 & 1.15 & $0.98,1.36$ & 0.093 \\
\hline $5-7$ & 2.37 & $0.94,6.05$ & 0.067 & 1.09 & $0.94,1.26$ & 0.253 \\
\hline$\geq 8$ & 2.77 & $1.13,6.96$ & 0.027 & 1.18 & $1.03,1.36$ & 0.021 \\
\hline Stroke (CVA) & 0.58 & $0.40,0.85$ & 0.005 & 0.92 & $0.85,1.00$ & 0.045 \\
\hline
\end{tabular}


Table 4 Subgroup analysis of home care clients with and without Parkinsonism in HNHB health region, Jan 1-Mar 31, 2018 (Continued)

\begin{tabular}{|c|c|c|c|c|c|c|}
\hline & Has $P$ & nism $(n=4$ & & Does & Parkinsonisr & \\
\hline & $\overline{\mathrm{IRR}}$ & $95 \% \mathrm{Cl}$ & $P$ Value & $\mathrm{IRR}$ & $95 \% \mathrm{Cl}$ & $P$ Value \\
\hline Congestive Heart Failure (CHF) & 0.85 & $0.52,1.63$ & 0.487 & 0.86 & $0.79,0.95$ & 0.001 \\
\hline Hypertension (HTN) & 0.91 & $0.70,1.18$ & 0.462 & 1.00 & $0.94,1.07$ & 0.950 \\
\hline Irregular Pulse & 1.11 & $0.78,1.60$ & 0.561 & 0.99 & $0.91,1.07$ & 0.739 \\
\hline Peripheral Vascular Disease (PVD) & 0.92 & $0.53,1.63$ & 0.762 & 0.97 & $0.87,1.07$ & 0.535 \\
\hline Chest Pain/Pressure at Rest or on Exertion & 0.75 & $0.34,1.74$ & 0.489 & 1.13 & $0.98,1.30$ & 0.094 \\
\hline Dizziness or Lightheadedness & 1.09 & $0.84,1.42$ & 0.518 & 1.45 & $1.35,1.55$ & $<0.001$ \\
\hline Edema & 0.73 & $0.56,1.63$ & 0.025 & 1.02 & 0.96 & 0.542 \\
\hline Shortness of Breath & 0.99 & $0.74,1.33$ & 0.947 & 0.91 & $0.85,0.98$ & 0.011 \\
\hline Alzheimer's & 0.81 & $0.44,1.52$ & 0.487 & 0.81 & $0.70,0.93$ & 0.002 \\
\hline Dementia & 0.97 & $0.70,1.34$ & 0.843 & 1.03 & $0.94,1.12$ & 0.569 \\
\hline Multiple Sclerosis (MS) & 2.27 & $0.59,9.92$ & 0.186 & 1.10 & $0.86,1.39$ & 0.452 \\
\hline Arthritis & 0.93 & $0.72,1.21$ & 0.593 & 1.05 & $0.98,1.12$ & 0.143 \\
\hline Hip Fracture & 0.77 & $0.40,1.51$ & 0.419 & 1.15 & $1.00,1.32$ & 0.057 \\
\hline
\end{tabular}

IRR Incident Rate Ratios, 95\% Cl 95\% Confidence Interval

compared to females, but men with neurological and cardiovascular health conditions had a decrease in the rate of falls compared to females. Home care clients with parkinsonism who used a cane indoors had a $129 \%$ increase in the rate of falls compared to those with parkinsonism who do not use an assistive device. Home care clients with parkinsonism who also took eight or more drugs had a $177 \%$ increase in the rate of falls compared to those who do not have parkinsonism.

Our findings confirm many of our hypotheses and are aligned with the existing literature describing accidental falls, assistive devices, and home care [31-34]. The increased rate of falls among health conditions (e.g., dizziness or lightheadedness, parkinsonism, etc.) was expected because these health conditions can cause individuals to be unstable on their feet and result in falls. The increased rate of falls attributed to assistive device use was an unexpected finding, given that we hypothesized the association between impaired cognitive skills for daily decision-making would have been higher. The decreased rate of falls among those who have had a stroke, live with congestive heart failure, shortness of breath, or Alzheimer's was expected because these individuals are less mobile or bed-ridden because of the pathology of these conditions, which decreases the likelihood of falling. Our findings are consistent with previous studies identifying an association between parkinsonism and falls [10, 35] and between multiple sclerosis, wheelchair use, and falls [36]. Our findings are also generalizable to the literature on home care and supporting older adults in their home because as more Canadian older adults are homebound [37], the likelihood of falls in the home increases. Understanding the associations with rates of falls among older adults in the home is important for identifying ways in which falls can be prevented to support healthy aging in the home and avert unnecessary emergency department use attributed to injuries. We additionally identified how the risk of cane use for locomotion indoors for increasing the rate of falls differs substantially between males and females and among home care clients with and without parkinsonism, which we believe is an important finding for clinicians, home health care practitioners (e.g., personal support works, nurses, etc.), and informal caregivers (e.g., family members, friends, etc.). This information will help the care team identify subgroups of home care clients who may be at increased risk for multiple falls and implement strategies to prevent them.

\section{Implications for policies and practices pertaining to home care}

Our findings underscore the importance of monitoring home care clients with a neurological health condition and who use an assistive device for locomotion indoors. Research on the use of a cane and gait changes among older adults with and without Alzheimer's disease found that learning to use this assistive device required increased cognition and resulted in poorer gait performance [38]. Previous studies identified people with multiple sclerosis or who use a wheelchair or scooter for locomotion indoors to be susceptible to fall, including sustaining injuries as a result of falling [36]. These findings identify that 
Table 5 Subgroup analysis of home care clients with and without dizziness or lightheadedness in the HNHB health region, Jan 1Mar 31, 2018

\begin{tabular}{|c|c|c|c|c|c|c|}
\hline & \multicolumn{3}{|c|}{ Has Dizziness or Lightheadedness $(n=2795)$} & \multicolumn{3}{|c|}{ Does Not Have Dizziness or Lightheadedness $(n=7791)$} \\
\hline & IRR & $95 \% \mathrm{Cl}$ & $P$ Value & IRR & $95 \% \mathrm{Cl}$ & $P$ Value \\
\hline \multicolumn{7}{|l|}{ Demographic Characteristics } \\
\hline Male & 1.00 & 1.00 & 1.00 & 1.00 & 1.00 & 1.00 \\
\hline Female & 0.80 & $0.72,0.90$ & $<0.001$ & 0.84 & $0.78,0.91$ & $<0.001$ \\
\hline \multicolumn{7}{|l|}{ Age } \\
\hline$<60$ & 1.00 & 1.00 & 1.00 & 1.00 & 1.00 & 1.00 \\
\hline $60-69$ & 0.85 & $0.68,1.07$ & 0.164 & 0.91 & $0.77,1.07$ & 0.243 \\
\hline $70-79$ & 0.61 & $0.49,0.76$ & $<0.001$ & 0.78 & $0.67,0.92$ & 0.002 \\
\hline $80-89$ & 0.56 & $0.45,0.70$ & $<0.001$ & 0.77 & $0.66,0.90$ & 0.001 \\
\hline $90-99$ & 0.58 & $0.45,0.74$ & $<0.001$ & 0.75 & $0.63,0.89$ & 0.001 \\
\hline$\geq 100$ & 0.90 & $0.38,2.40$ & 0.824 & 0.50 & $0.30,0.84$ & 0.008 \\
\hline \multicolumn{7}{|l|}{ Marital Status } \\
\hline Never Married & 1.11 & $0.89,1.39$ & 0.365 & 0.88 & $0.76,1.02$ & 0.097 \\
\hline Married & 1.00 & 1.00 & 1.00 & 1.00 & 1.00 & 1.00 \\
\hline Widowed & 1.02 & $0.90,1.16$ & 0.744 & 0.96 & $0.88,1.05$ & 0.366 \\
\hline Separated & 1.24 & $0.91,1.72$ & 0.176 & 1.26 & $1.02,1.55$ & 0.296 \\
\hline Divorced & 1.05 & $0.87,1.27$ & 0.621 & 1.06 & $0.92,1.22$ & 0.386 \\
\hline Other & 1.59 & $1.11,2.31$ & 0.012 & 1.03 & $0.78,1.37$ & 0.842 \\
\hline \multicolumn{7}{|l|}{ Functional Characteristics } \\
\hline \multicolumn{7}{|c|}{ Cognitive Skills for Daily Decision-Making } \\
\hline Independent & 1.00 & 1.00 & 1.00 & 1.00 & 1.00 & 1.00 \\
\hline Modified Independence & 1.12 & $0.97,1.28$ & 0.110 & 1.17 & $1.06,1.29$ & 0.001 \\
\hline Minimally Impaired & 1.23 & $1.05,1.43$ & 0.008 & 1.33 & $1.20,1.48$ & $<0.001$ \\
\hline Moderately Impaired & 1.28 & $1.04,1.58$ & 0.017 & 1.45 & $1.27,1.65$ & $<0.001$ \\
\hline Severely Impaired & 1.55 & $1.14,2.10$ & 0.004 & 1.16 & $0.99,1.36$ & 0.065 \\
\hline Activities of Daily Living Decline & 1.41 & $1.25,1.60$ & $<0.001$ & 1.65 & $1.53,1.79$ & $<0.001$ \\
\hline \multicolumn{7}{|c|}{ Primary Modes of Locomotion (Indoors) } \\
\hline No Assistive Device & 1.00 & 1.00 & 1.00 & 1.00 & 1.00 & 1.00 \\
\hline Cane & 1.38 & $1.15,1.66$ & $<0.001$ & 1.45 & $1.27,1.67$ & $<0.001$ \\
\hline Walker/Crutch & 1.46 & $1.25,1.60$ & $<0.001$ & 1.51 & $1.36,1.67$ & $<0.001$ \\
\hline Scooter & 2.12 & $1.00,4.83$ & $<0.052$ & 2.37 & $1.32,4.43$ & 0.004 \\
\hline Wheelchair & 1.62 & $1.32,1.99$ & $<0.001$ & 1.28 & $1.12,1.45$ & $<0.001$ \\
\hline Activity Did Not Occur & 0.54 & $0.27,1.08$ & 0.081 & 1.16 & $0.88,1.54$ & 0.282 \\
\hline \multicolumn{7}{|l|}{ Stair Climbing } \\
\hline Up and Down Stairs No Help & 1.00 & 1.00 & 1.00 & 1.00 & 1.00 & 1.00 \\
\hline Up and Down Stairs with Help & 1.19 & $1.00,1.41$ & 0.057 & 1.22 & $1.08,1.38$ & 0.001 \\
\hline Not Go Up and Down Stairs & 1.20 & $1.03,1.41$ & 0.023 & 1.23 & $1.10,1.37$ & $<0.001$ \\
\hline \multicolumn{7}{|l|}{ Polypharmacy and Health Conditions } \\
\hline \multicolumn{7}{|l|}{ Drugs } \\
\hline $0-2$ & 1.00 & 1.00 & 1.00 & 1.00 & 1.00 & 1.00 \\
\hline $3-4$ & 1.21 & $0.85,1.72$ & 0.292 & 1.19 & $0.99,1.44$ & 0.064 \\
\hline $5-7$ & 1.18 & $0.86,1.61$ & 0.301 & 1.07 & $0.91,1.26$ & 0.435 \\
\hline$\geq 8$ & 1.23 & $0.91,1.67$ & 0.174 & 1.18 & $1.01,1.39$ & 0.038 \\
\hline
\end{tabular}


Table 5 Subgroup analysis of home care clients with and without dizziness or lightheadedness in the HNHB health region, Jan 1Mar 31, 2018 (Continued)

\begin{tabular}{|c|c|c|c|c|c|c|}
\hline & \multicolumn{3}{|c|}{ Has Dizziness or Lightheadedness $(n=2795)$} & \multicolumn{3}{|c|}{ Does Not Have Dizziness or Lightheadedness $(n=7791)$} \\
\hline & IRR & $95 \% \mathrm{Cl}$ & $P$ Value & IRR & $95 \% \mathrm{Cl}$ & $P$ Value \\
\hline Stroke (CVA) & 0.88 & $0.77,1.00$ & 0.053 & 0.92 & $0.83,1.01$ & 0.069 \\
\hline Congestive Heart Failure (CHF) & 0.92 & $0.79,1.06$ & 0.246 & 0.84 & $0.75,0.94$ & 0.002 \\
\hline Hypertension (HTN) & 0.95 & $0.85,1.07$ & 0.428 & 1.00 & $0.93,1.09$ & 0.951 \\
\hline Irregular Pulse & 1.08 & $0.95,1.23$ & 0.217 & 0.95 & $0.86,1.05$ & 0.314 \\
\hline Peripheral Vascular Disease (PVD) & 0.96 & $0.81,1.14$ & 0.661 & 0.97 & $0.85,1.10$ & 0.608 \\
\hline Chest Pain/Pressure at Rest or on Exertion & 1.01 & $0.84,1.21$ & 0.937 & 1.26 & $1.01,1.57$ & 0.037 \\
\hline Edema & 0.95 & $0.86,1.06$ & 0.403 & 1.02 & $0.95,0.86$ & 0.566 \\
\hline Shortness of Breath & 0.93 & $0.84,1.04$ & 0.217 & 1.26 & $1.01,1.57$ & 0.018 \\
\hline Alzheimer's & 0.91 & $0.70,1.18$ & 0.467 & 0.75 & $0.64,0.87$ & $<0.001$ \\
\hline Dementia & 1.15 & $0.99,1.34$ & 0.071 & 0.96 & $0.87,1.06$ & 0.395 \\
\hline Multiple Sclerosis (MS) & 1.18 & $0.77,1.83$ & 0.453 & 1.05 & $0.80,1.40$ & 0.175 \\
\hline Parkinsonism & 1.22 & $0.98,1.53$ & 0.074 & 1.59 & $1.35,1.88$ & $<0.001$ \\
\hline Arthritis & 0.97 & $0.87,1.09$ & 0.637 & 1.07 & $0.99,1.15$ & 0.090 \\
\hline Hip Fracture & 0.89 & $0.68,1.15$ & 0.357 & 1.22 & $1.04,1.44$ & 0.014 \\
\hline
\end{tabular}

IRR Incident Rate Ratios, 95\% Cl 95\% Confidence Interval

assistive device use might precipitate falling among home care clients with a neurological health condition, and these findings are relevant to the work of individuals tasked with coordinating home care and home health care practitioners to help prevent accidental falls among higher risk patient groups. The use of assistive devices for locomotion indoors, such as canes and walkers, by home care clients is typically a supportive measure to prevent falls, and previous studies have identified that falls occurred when clients were not using these assistive devices [39]. The use of canes and/or walkers may also be attributed to the fact that these users may be weaker than non-users, and so these users may be more susceptible to falls. Individuals responsible for coordinating home care and home health care practitioners should be aware of assistive device use for locomotion and discuss and monitor safe use the use of the device with the client and other informal caregivers to limit the possibility of accidental falls in the home.

Our findings are also relevant to clinicians and policymakers in the areas of patient safety and quality improvement as these relate to home care. Specifically, our identification of the statistically significant associations between assistive device use for locomotion indoors and the rate of falls supports the idea of implementing interventions that reduce frailty and the occurrence of falls through exercise programs. A systematic review examining community-based exercise interventions found that these interventions are valuable for reducing the incidence of falls when these interventions focus on improving balance and include functional and resistance exercises [40]. A randomized controlled trial from Norway on exercise programs also found positive results with respect to improving physical health-related quality of life [41]. These findings demonstrate the value of exercise interventions for home care clients to reduce the incidence of accidental falls and improve patient safety in home care settings.

\section{Strengths and limitations}

Our research is novel because we conducted a comprehensive, explanatory analysis of the associations with person-level characteristics with falls among home care clients in a population-based sample. We also identified strong, statistically significant associations between multiple assistive devices for locomotion indoors and falls. Our findings are strengthened by our large sample size and statistical power.

There are limitations to our research. First, our research is descriptive, rather than analytic. As such, a temporal sequence identifying whether assistive device occurred before or after the first occurrence of an accidental fall could not be determined, and this also limits the ability to make causal claims about assistive device use and the rate of falls in the home care setting. Second, we could not determine where in the home the fall occurred (e.g., fall down the stairs; fall from standing; fall in the bedroom, kitchen, washroom, etc.), which affects decisions pertaining to in-home environmental 
Table 6 Subgroup analysis of home care clients with and without congestive heart failure in the HNHB health region, Jan 1-Mar 31, 2018

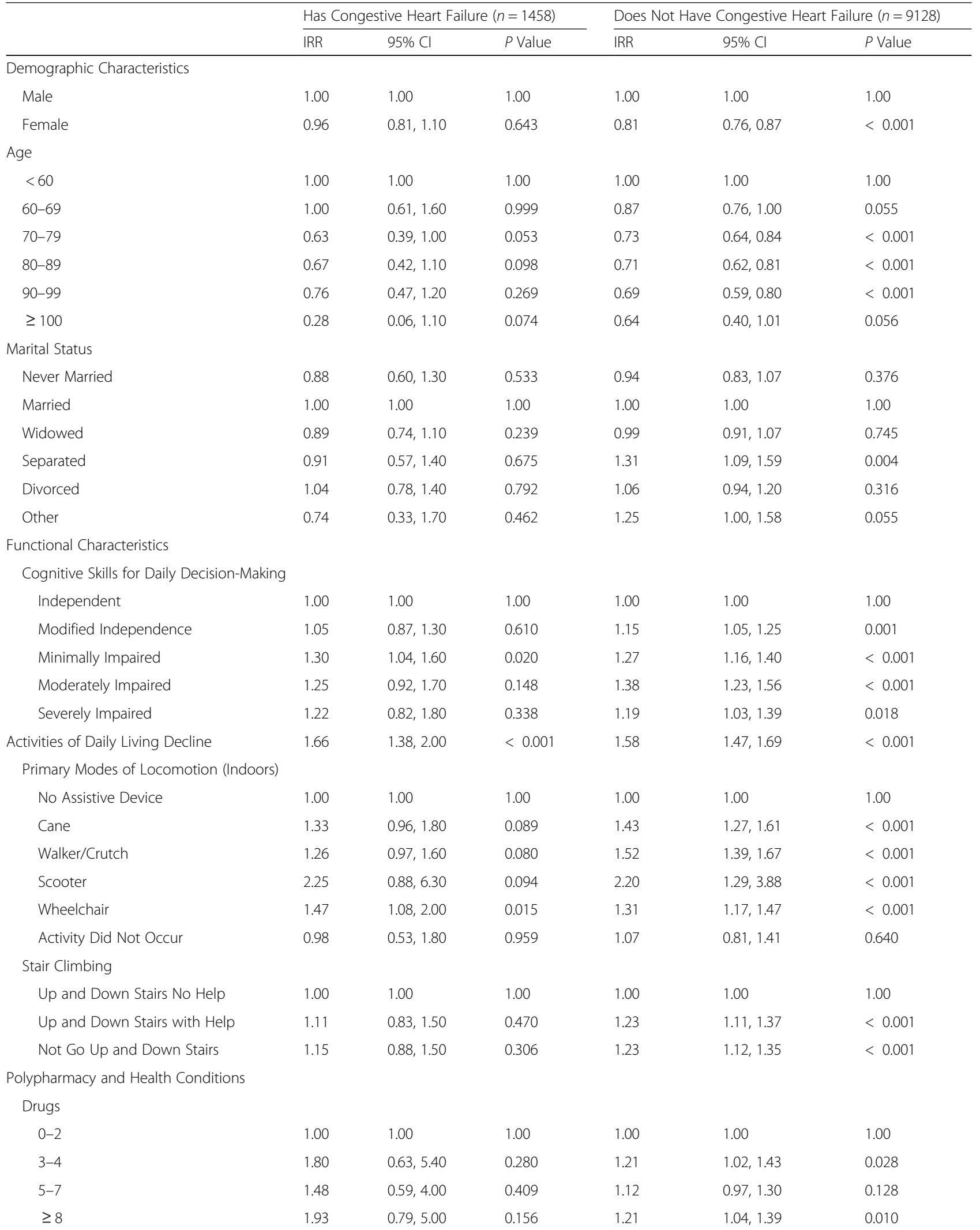


Table 6 Subgroup analysis of home care clients with and without congestive heart failure in the HNHB health region, Jan 1-Mar 31, 2018 (Continued)

\begin{tabular}{|c|c|c|c|c|c|c|}
\hline & \multicolumn{3}{|c|}{ Has Congestive Heart Failure $(n=1458)$} & \multicolumn{3}{|c|}{ Does Not Have Congestive Heart Failure $(n=9128$} \\
\hline & IRR & $95 \% \mathrm{Cl}$ & $P$ Value & $\overline{\mathrm{IRR}}$ & $95 \% \mathrm{Cl}$ & $P$ Value \\
\hline Stroke (CVA) & 0.94 & $0.78,1.10$ & 0.483 & 0.90 & $0.83,0.98$ & 0.014 \\
\hline Hypertension (HTN) & 1.13 & $0.93,1.40$ & 0.216 & 0.98 & $0.91,1.05$ & 0.486 \\
\hline Irregular Pulse & 0.86 & $0.74,1.00$ & 0.067 & 1.03 & $0.95,1.13$ & 0.443 \\
\hline Peripheral Vascular Disease (PVD) & 1.00 & $0.82,1.20$ & 0.969 & 0.95 & $0.84,1.07$ & 0.379 \\
\hline Chest Pain/Pressure at Rest or on Exertion & 1.04 & $0.80,1.30$ & 0.788 & 1.12 & $0.95,1.32$ & 0.185 \\
\hline Dizziness or Lightheadedness & 1.47 & $1.25,1.70$ & $<0.001$ & 1.41 & $1.31,1.52$ & $<0.001$ \\
\hline Edema & 1.10 & $0.94,1.30$ & 0.244 & 1.00 & $0.93,1.07$ & 0.985 \\
\hline Shortness of Breath & 0.88 & $0.75,1.00$ & 0.138 & 0.92 & $0.86,0.99$ & 0.032 \\
\hline Alzheimer's & 1.26 & $0.86,1.90$ & 0.228 & 0.77 & $0.66,0.89$ & $<0.001$ \\
\hline Dementia & 1.16 & $0.93,1.50$ & 0.187 & 1.01 & $0.92,1.10$ & 0.905 \\
\hline Multiple Sclerosis (MS) & 0.48 & $0.88,1.20$ & 0.265 & 1.12 & $0.89,1.43$ & 0.337 \\
\hline Parkinsonism & 1.22 & $0.80,1.90$ & 0.358 & 1.49 & $1.29,1.71$ & $<0.001$ \\
\hline Arthritis & 1.04 & $0.88,1.20$ & 0.633 & 1.04 & $0.97,1.11$ & 0.246 \\
\hline Hip Fracture & 1.01 & $0.70,1.50$ & 0.976 & 1.16 & $1.00,1.34$ & 0.052 \\
\hline
\end{tabular}

IRR Incident Rate Ratios, 95\% Cl 95\% Confidence Interval

adjustments to reduce or eliminate falls. Third, our subgroup analysis of home care clients with a parkinsonism diagnosis is underpowered.

\section{Conclusion}

Declines in activities of daily living, the use of assistive devices for locomotion indoors, impaired cognitive skills for daily decision-making, parkinsonism, and experiencing dizziness or lightheadedness are important associations with rate of falls among home care clients in Ontario, Canada. Future research could investigate, compare, and contrast the use assistive devices for locomotion outdoors and falls frequency among home care clients in other jurisdictions.

\section{Appendix}

\section{Abbreviations}

95\% Cl: 95\% Confidence Interval; HNHB: Hamilton, Niagara, Haldimand, and Brant; IRR: Incident Rate Ratio; RAI-HC: Resident Assessment Instrument Home Care

\section{Acknowledgements}

None.

\section{Authors' contributions}

DRM conceptualized the study, conducted the data analysis, interpreted the results, and wrote the manuscript. CM provided content expertise and assisted with the interpretation of the results. APC supervised, provided input to the study design, and assisted with the interpretation of the results. All authors critically read, contributed to, and approved the manuscript for submission.

\section{Funding}

Andrew P. Costa is supported by the Schlegel Chair in Clinical Epidemiology \& Aging, McMaster University. This work was supported by Canadian
Institutes of Health Research (CIHR; grant number 148933). The funders had no role in the design of the study, interpretation of data, or decision to submit results.

\section{Availability of data and materials}

The data analyzed in this study are not publicly available due to privacy and confidentiality restrictions pertaining to person-level health information, which contains personal identifiers, in Ontario, Canada; however, the data set creation plan and underlying analytic code are available from the corresponding author on reasonable request.

\section{Ethics approval and consent to participate}

We received ethics approval from the Hamilton Integrated Research Ethics Board (\#14-498-D). The need for verbal and/or written consent from participants for secondary use of health information is deemed unnecessary as per the Personal Health Information Protection Act, 2004.

\section{Consent for publication}

Not applicable.

\section{Competing interests}

The authors declare that they have no competing interests.

\section{Author details}

${ }^{1}$ Centre for Health Economics and Policy Analysis, McMaster University, 1280 Main Street West, CRL-201, Hamilton, ON L8S 4K1, Canada. ${ }^{2}$ Department of Health Research Methods, Evidence, and Impact, McMaster University, Hamilton, Canada. ${ }^{3}$ Department of Medicine, McMaster University, Hamilton, Canada. ${ }^{4}$ GERAS Centre for Aging Research, McMaster University, Hamilton, Canada.

Received: 15 November 2019 Accepted: 17 February 2020

Published online: 27 February 2020

\section{References}

1. Kuspinar A, Hirdes JP, Berg K, MCArthur C, Morris JN. Development and validation of an algorithm to assess risk of first-time falling among home care clients. BMC Geriatr. 2019;19:264.

2. Public Health Agency of Canada. Seniors' falls in Canada. Ottawa: Public Health Agency of Canada; 2014. 
3. Isaranuwatchai W, Perdrizet J, Markle-Reid M, Hoch JS. Cost-effectiveness analysis of a multifactorial fall prevention intervention in older home care clients at risk for falling. BMC Geriatr. 2017;17:199.

4. Sinn C-LJ, Betini RSD, Wright J, Eckler L, Chang BW, Hogeveen S, et al. Adverse events in home care: identifying and responding with interRAI scales and clinical assessment protocols. Can J Aging. 2018;37:60-9.

5. Byers AL, Sheeran T, Mlodzianowski AE, Meyers BS, Nassisi P, Bruce ML. Depression and risk for adverse falls in older home health care patients. Res Gerontol Nurs. 2008;1:245-51.

6. Bjerk M, Brovold T, Skelton DA, Bergland A. Associations between healthrelated quality of life, physical function and fear of falling in older fallers receiving home care. BMC Geriatr. 2018;18:253.

7. Lavis JN, Hammill AC. Care by sector. In: Lavis JN, editor. Ontario's health system: key insights for engaged citizens, professionals and policymakers. Hamilton: McMaster Health Forum; 2017. p. 209-70.

8. Guthrie DM, Harman LE, Barbera L, Burge F, Lawson B, McGrail K, et al. Quality Indicator rates for seriously ill home care clients: analysis of resident assessment instrument for home care data in six Canadian provinces. J Palliat Med. 2019;22:1346-56.

9. Shaw J, Bastawrous M, Burns S, McKay S. System issues leading to "foundon-floor" incidents: a multi-incident analysis. J Patient Saf. 2016. https://doi. org/10.1097/PTS.0000000000000294. [Epub ahead of print]

10. Bansal S, Hirdes JP, Maxwell CJ, Papaioannou A, Giangregorio LM. Identifying fallers among home care clients with dementia and Parkinson's disease. Can J Aging. 2016:35:319-31.

11. Mondor L, Maxwell CJ, Bronskill SE, Gruneir A, Wodchis WP. The relative impact of chronic conditions and multimorbidity on health-related quality of life in Ontario long-stay home care clients. Qual Life Res. 2016;25:261932.

12. Poss JW, Sinn C-LJ, Grinchenko G, Blums J, Peirce T, Hirdes J. Location, location, location: characteristics and Services of Long-Stay Home Care Recipients in retirement homes compared to others in private homes and long-term care homes. Healthc Policy. 2017;12:80-93.

13. Schluter PJ, Ahuriri-Driscoll A, Anderson TJ, Beere P, Brown J, DalrympleAlford J, et al. Comprehensive clinical assessment of home-based older persons within New Zealand: an epidemiological profile of a national crosssection. Aust N Z J Public Health. 2016;40:349-55.

14. Jamieson HA, Nishtala PS, Scrase R, Deely JM, Abey-Nesbit R, Connolly MJ, et al. Drug burden and its association with falls among older adults in New Zealand: a National Population Cross-Sectional Study. Drugs Aging. 2018;35: 73-81.

15. Doran D, Hirdes JP, Blais R, Baker GR, Poss JW, Li X, et al. Adverse events associated with hospitalization or detected through the RAI-HC assessment among Canadian home care clients. Healthc Policy. 2013;9:76-88.

16. Mitchell LA, Hirdes J, Poss JW, Slegers-Boyd C, Caldarelli H, Martin L. Informal caregivers of clients with neurological conditions: profiles, patterns and risk factors for distress from a home care prevalence study. BMC Health Serv Res. 2015;15:350.

17. Mofina AM, Guthrie DM. A comparison of home care quality indicator rates in two Canadian provinces. BMC Health Serv Res. 2014;14:37.

18. Vu M, Hogan DB, Patten SB, Jette N, Bronskill SE, Heckman G, et al. A comprehensive profile of the sociodemographic, psychosocial and health characteristics of Ontario home care clients with dementia. Chronic Dis Inj Can. 2014;34:132-44.

19. Harrell FE. Regression modeling strategies: with applications to linear models, logistic regression, and survival analysis. 2nd ed. London: Springer; 2001.

20. Fox J. Effect displays in $\mathrm{R}$ for generalised linear models. J Stat Softw. 2003;8: $1-27$.

21. Grosjean P, Ibanez F. pastecs: Package for Analysis of Space-Time Ecological Series. 2018. https://CRAN.R-project.org/package=pastecs.

22. $R$ Core Team. $R$ : a language and environment for statistical computing. $R$ Foundation for Statistical Computing; 2019.

23. Robinson D, Hayes A. broom: Convert Statistical Analysis Objects into Tidy Tibbles. 2019. https://CRAN.R-project.org/package=broom

24. Signorell A. DescTools: tools for descriptive statistics. 2019. https://cran.rproject.org/package=DescTools.

25. Tang Y, Horikoshi M, Li W. ggfortify: Unified Interface to Visualize Statistical Result of Popular R Packages. R J. 2016;82:478-89.

26. Venables WN, Ripley BD. Modern applied statistics with S. New York: Springer; 2002.
27. Wickham H. tidyverse: Easily install and load the 'Tidyverse'. 2017. https:// CRAN.R-project.org/package=tidyverse.

28. Wickham H. modelr: Modelling Functions that Work with the Pipe. 2019. https://CRAN.R-project.org/package=modelr.

29. Wickham H, Hester J, Francois R. readr: Read Rectangular Text Data. 2018. https://CRAN.R-project.org/package=readr.

30. Hsu AT, Manuel DG, Taljaard M, Chalifoux M, Bennett C, Costa AP, et al. Algorithm for predicting death among older adults in the home care setting: study protocol for the risk evaluation for support: predictions for elder-life in the community tool (RESPECT). BMJ Open. 2016;6:e013666.

31. Kanters DM, Griffith LE, Hogan DB, Richardson J, Patterson C, Raina P. Assessing the measurement properties of a frailty index across the age spectrum in the Canadian longitudinal study on aging. J Epidemiol Community Health. 2017;71:794-9.

32. Boffin N, Moreels S, Vanthomme K, Van Casteren V. Falls among older general practice patients: a 2-year nationwide surveillance study. Fam Pract. 2014;31:281-9.

33. Gianni C, Prosperini L, Jonsdottir J, Cattaneo D. A systematic review of factors associated with accidental falls in people with multiple sclerosis: a meta-analytic approach. Clin Rehabil. 2014;28:704-16.

34. Walsh M, Galvin R, Horgan NF. Fall-related experiences of stroke survivors: a meta-ethnography. Disabil Rehabil. 2017:39:631-40.

35. Poss JW, Hirdes JP. Very frequent fallers and future fall injury: continuous risk among community-dwelling home care recipients. J Aging Health. 2016;28: 587-99.

36. Rice L, Kalron A, Berkowitz SH, Backus D, Sosnoff JJ. Fall prevalence in people with multiple sclerosis who use wheelchairs and scooters. Medicine (Baltimore). 2017:96:e7860

37. Akhtar S, Loganathan M, Nowaczynski M, Sinha S, Condon A, Ewa V, et al. Aging at home: a portrait of home-based primary care across Canada. Healthc Q. 2019:22:30-5.

38. Hunter SW, Divine A, Omana H, Wittich W, Hill KD, Johnson AM, et al. Effect of learning to use a mobility aid on gait and cognitive demands in people with mild to moderate Alzheimer's disease: part I - cane. J Alzheimers Dis. 2019:71:S105-14.

39. Luz C, Bush T, Shen X. Do canes or walkers make any difference? Non Use and Fall Injuries. Gerontologist. 2017:57:211-8.

40. Sherrington C, Fairhall NJ, Wallbank GK, Tiedemann A, Michaleff ZA, Howard $\mathrm{K}$, et al. Exercise for preventing falls in older people living in the community. Cochrane Database Syst Rev. 2019. https://doi.org/10.1002/ 14651858.CD012424.pub2

41. Bjerk M, Brovold T, Davis JC, Skelton DA, Bergland A. Health-related quality of life in home care recipients after a falls prevention intervention: a 6month follow-up. Eur J Pub Health. 2019:30:64-9.

\section{Publisher's Note}

Springer Nature remains neutral with regard to jurisdictional claims in published maps and institutional affiliations.

Ready to submit your research? Choose BMC and benefit from:

- fast, convenient online submission

- thorough peer review by experienced researchers in your field

- rapid publication on acceptance

- support for research data, including large and complex data types

- gold Open Access which fosters wider collaboration and increased citations

- maximum visibility for your research: over $100 \mathrm{M}$ website views per year

At BMC, research is always in progress.

Learn more biomedcentral.com/submission 